\title{
PROCESSOS FORMATIVOS DE PROFESSORES SUPERVISORES NO ÂMBITO DO PIBID: SENTIDOS ATRIBUÍDOS ÀS ATIVIDADES EXPERIENCIADAS NA UNIVERSIDADE E NA ESCOLA
}

\author{
PROCESOS FORMATIVOS DE PROFESORES SUPERVISORES EN EL AMBITO DEL \\ PIBID: SENTIDOS ATRIBUIDOS A LAS ACTIVIDADES VIVIDAS EN LA \\ UNIVERSIDAD Y EN LA ESCUELA
}

\begin{abstract}
FORMATIVE PROCESSES OF SUPERVISORY TEACHERS IN THE CONTEXT OF PIBID: MEANINGS ASSIGNED TO ACTIVITIES EXPERIENCED AT UNIVERSITY AND SCHOOL
\end{abstract}

\author{
Sandra Alves de OLIVEIRA ${ }^{1}$ \\ Dayselane Pimenta Lopes REZENDE ${ }^{2}$ \\ Reginaldo Fernando CARNEIRO ${ }^{3}$
}

RESUMO: Este artigo tem como objetivo compreender os sentidos atribuídos pelos professores supervisores do Programa Institucional de Bolsa de Iniciação à Docência (Pibid) às atividades experienciadas na universidade e nas escolas parceiras no âmbito do subprojeto Laboratório de Práticas Pedagógicas. Procurou-se, por meio de um estudo analítico-descritivo, analisar e discutir dados dos relatórios produzidos pelos oito professores supervisores participantes do subprojeto do Pibid, no período de 2014 a 2017, em parceria com estudantes bolsistas de Iniciação à Docência (ID), as professoras formadoras coordenadoras de área do Departamento de Educação da Universidade do Estado da Bahia e os professores coformadores das quatro escolas da educação básica da rede municipal de ensino de Guanambi, estado da Bahia, que participaram deste programa. A análise dos dados indica que as atividades desenvolvidas pelos professores supervisores na universidade e nas escolas parceiras do subprojeto Laboratório de Práticas Pedagógicas, por meio da participação nos grupos colaborativos de estudo no contexto da formação e da prática docente, possibilitaram o compartilhamento de saberes, experiências e aprendizagens da formação e da prática docente. O Pibid constitui-se como uma alternativa de estabelecimento dessa parceria, aproximando a universidade da educação básica, por meio de um trabalho colaborativo.

PALAVRAS-CHAVE: Formação de professores. Programa de iniciação à docência. Integração escola-universidade.

${ }^{1}$ Universidade Federal de Juiz de Fora (UFJF), Juiz de Fora - MG - Brasil. Doutoranda no Programa de PósGraduação em Educação. Integra os Grupos de Pesquisas: NEPE/Campus XII/UNEB, GEM/UFSCar, GREPEM/UFJF. ORCID: https://orcid.org/0000-0002-7804-7197. E-mail: saoliveira@uneb.br

${ }^{2}$ Universidade Federal de Juiz de Fora (UFJF), Juiz de Fora - MG - Brasil. Doutoranda no Programa de PósGraduação em Educação. ORCID: https://orcid.org/0000-0001-8846-3234. E-mail: lanedayse@gmail.com

${ }^{3}$ Universidade Federal de Juiz de Fora (UFJF), Juiz de Fora - MG - Brasil. Professor no Programa de PósGraduação em Educação e no Programa de Pós-Graduação em Educação Matemática. Doutorado em Educação (UFSCAR). ORCID: https://orcid.org/0000-0001-6841-7695. E-mail: reginaldo.carneiro@ufjf.edu.br

RIAEE - Revista Ibero-Americana de Estudos em Educação, Araraquara, v. 16, n. esp. 1, p. 982-998, mar. 2021. e-ISSN: 1982-5587 
RESUMEN: Este artículo tiene como objetivo comprender los sentidos atribuidos por los profesores supervisores del Programa Institucional de Becas de Iniciación a la Docencia (PIBID) a las actividades vividas en la universidad y en las escuelas que participaron del sub proyecto Laboratorio de Prácticas Pedagógicas. Se buscó, por medio de un estudio analíticodescriptivo, analizar y discutir los datos de los relatos técnicos producidos por ocho profesores supervisores participantes del sub proyecto del Pibid, en el periodo de 2014 a 2017, en conjunto con estudiantes becarios de Iniciación a la Docencia (ID) y las profesoras formadoras coordinadoras del área del Departamento de Educación de la Universidad del Estado de Bahía y los profesores coformadores de cuatro escuelas de educación básica de la red municipal de enseñanza de Guanambi, estado de Bahía, que participaron de este programa. El análisis de datos indicó que las actividades desarrolladas por los profesores supervisores en la universidad y en las escuelas del subproyecto Laboratorio de Prácticas Pedagógicas, por medio de la participación en los grupos colaborativos del estudio en el contexto de la formación y de la práctica docente, posibilitaron el compartir de saberes, experiencias y aprendizajes de la formación y de la práctica docente. El Pibid se constituyó como una alternativa de establecimiento de ese trabajo conjunto, acercando la universidad de la educación básica, por medio de un trabajo colaborativo.

PALABRAS CLAVE: Formación del profesorado. Programa de iniciación a la docencia. Integración escuela-universidad.

ABSTRACT: This article aims to understand the meanings attributed by the supervising professors of the Institutional Program for Teaching Initiation Scholarships (Pibid) to the activities experienced at the university and in the partner schools within the subproject Laboratory of Pedagogical Practices. We sought, through an analytical-descriptive study, to analyze and discuss data from the reports produced by the eight supervising professors participating in the subproject of Pibid, in the period from 2014 to 2017, in partnership with scholarship students from Teaching Initiation (ID) and the teacher coordinators in the area of Education Department of Bahia State and the co-forming teachers of the four schools of basic education in the municipal teaching network of Guanambi, state of Bahia, who participated in this program. The analysis of the data indicates that the activities developed by the supervising professors at the university and in the partner schools of the Laboratory of Pedagogical Practices subproject, through participation in collaborative study groups in the context of teacher education and practice, made it possible to share knowledge, experiences and learning from teacher education and practice. Pibid is an alternative to establish this partnership, bringing the university closer to basic education, through a collaborative.

KEYWORDS: Teacher education. Teaching initiation program. School-university integration.

\section{Introdução}

A partir do aporte teórico estudado na disciplina "Culturas, Linguagens e Formação de Professores", mediada pelas Professoras Dra. Hilda Micarello e Dra. Tânia Guedes Magalhães, do curso do Programa de Pós-Graduação em Educação (PPGE) da Universidade Federal de Juiz de Fora, estado de Minas Gerais, refletimos sobre as contribuições e as 
perspectivas da filosofia da linguagem; sobre a questão do sentido; e também sobre gêneros do discurso e seu papel nos debates sobre os letramentos; sobre pesquisa em ciências humanas, letramento, linguagem, escola e formação de professores; sobre formação de professores - formação pela escrita autoral e pela pesquisa; sobre redes colaborativas de professores e imersão no contexto de trabalho, práticas formativas em grupos colaborativos; sobre materiais didáticos; e sobre multiletramentos.

As reflexões teóricas e práticas sobre esses temas nas aulas desta disciplina, nos momentos "de encontros entre sujeitos mediados pela linguagem" (MICARELLO; MAGALHÃES, 2014, p. 156), numa prática interativa entre os interlocutores (estudantes da Pós-Graduação e professoras), possibilitaram-nos compreender os conceitos de linguagem, sentido, diálogo e mediação, dentre outros, nas perspectivas bakhtiniana e vygotskyana, pouco estudadas nos percursos formativos das autoras deste trabalho.

Ao definirmos a temática do trabalho de conclusão da disciplina, sentimo-nos instigadas a pesquisar os processos de formação no âmbito do subprojeto Laboratório de Práticas Pedagógicas (Laprape) do Programa Institucional de Bolsa de Iniciação à Docência (Pibid), no curso de Pedagogia do Departamento de Educação (DEDC) de Guanambi, Campus XII da Universidade do Estado da Bahia (Uneb). Nossa motivação decorreu da atuação da primeira autora deste trabalho nesse subprojeto como bolsista de coordenação de área, no período de 2014 a 2017, e da segunda autora como supervisora nesse programa na Escola Municipal Boa Ventura, no município de Varre-Sai, estado do Rio de Janeiro, no período de 2014 a 2015.

O Pibid possibilita "um novo olhar para a escola, como campo de geração de conhecimentos que devem ser seriamente considerados pela universidade e incorporados aos projetos de formação inicial" (ANDRÉ, 2016, p. 52), com a participação de professores da universidade que atuam no processo formativo dos futuros professores, em parceria com os professores coformadores da educação básica que acompanham e orientam as atividades dos licenciandos nas escolas parceiras.

Os grupos constituídos nesses espaços formativos, numa perspectiva colaborativa, "podem desenvolver ações que tornam efetiva a parceria entre a universidade e a escola e contribuir para bons resultados na formação dos professores, e, consequentemente, no aprendizado dos alunos" (PASSOS, 2016, p. 167). As ações desenvolvidas no Laprape, no período de 2014 a 2017, "visando estreitar a distância entre universidade e escola e favorecer a inserção à docência" (ANDRÉ, 2016, p. 49), contemplaram as seguintes atividades: encontros formativos no Grupo de Estudo Laboratório de Práticas Pedagógicas, no Campus 
XII/Uneb, e nas escolas parceiras do Pibid; imersão e atuação na escola parceira do Pibid; realização de oficinas pedagógicas na universidade e nas escolas, com temáticas pertinentes à prática educativa em classes da educação infantil e dos anos iniciais do ensino fundamental; produção de relatórios, relatos de experiências e artigos científicos, divulgando-os em eventos locais, regionais, estaduais e nacionais.

Levando em consideração o desenvolvimento dessas práticas no percurso formativo dos professores supervisores da educação básica que participaram desse programa, buscamos, neste trabalho, compreender quais sentidos atribuem os professores supervisores do Pibid às atividades experienciadas na universidade e nas escolas parceiras do subprojeto Laprape.

Este texto discute dados dos relatórios produzidos pelos oito professores supervisores participantes deste subprojeto do Pibid, no período de 2014 a 2017, em parceria com estudantes bolsistas de Iniciação à Docência (ID), as professoras formadoras coordenadoras de área do DEDC XII/Uneb e os professores coformadores das quatro escolas da educação básica da rede municipal de ensino de Guanambi, estado da Bahia, que participaram desse programa. "É fundamental que haja mobilidade entre as universidades e as escolas. É preciso que todos tenham um estatuto de formador, universitários e professores da educação básica" (NÓVOA, 2017, p. 1117) e participem colaborativamente dos processos formativos entre os pares, numa relação dialógica, a partir de construções discursivas, nas quais os sujeitos e os sentidos se constituem discursivamente nas interações verbais estabelecidas na relação com o outro, nas esferas da atividade humana (BAKHTIN, 2011), mediatizadas pelos encontros dinâmicos, dialógicos, discursivos, problematizadores e interativos.

Na perspectiva bakhtiniana, "o sentido participa da categoria de diálogo, [...] só o sentido responde a perguntas" (BAKHTIN, 2011, p. 11), comunicadas dialogicamente no encontro com os sujeitos que participam da atividade humana, numa relação dialógicodiscursiva estabelecida entre os interlocutores.

Neste artigo, interessa-nos compreender os sentidos atribuídos pelos professores supervisores do Pibid às atividades experienciadas na universidade e nas escolas parceiras, no período de 2015 a 2017, por meio da relação dialógica estabelecida nas interações verbais e discursivas de enunciações possíveis (BAKHTIN; VOLOCHÍNOV, 1997) nesses espaços formativos de interlocução e diálogos.

\section{O Pibid no contexto da formação de professores}


O Programa Institucional de Bolsa de Iniciação à Docência (Pibid), criado em 2007, no contexto da Coordenação de Aperfeiçoamento de Pessoal de Nível Superior (Capes), ligada ao Ministério da Educação (MEC), aproxima a universidade à escola, com a finalidade de valorizar a formação de professores para atuação na educação básica e "fomentar a iniciação à docência, contribuindo para o aperfeiçoamento da formação de docentes em nível superior e para a melhoria da qualidade da educação básica pública brasileira" (BRASIL, 2013, p. 2).

A concessão de bolsas nesse programa é importante, visto que os bolsistas utilizam parte da sua carga horária semanal para o desenvolvimento das atividades propostas e criadas no contexto do subprojeto nas escolas parceiras. A esse respeito, André (2016, p. 50) destaca: "Para que os universitários sejam devidamente acompanhados e orientados, há bolsas para professores formadores da universidade e para professores que supervisionam os licenciandos nas escolas".

Esse programa oportuniza aos estudantes do curso de Pedagogia e de outras licenciaturas um maior contato com a educação básica, pois possibilita a imersão no cotidiano escolar por um período mais longo, contínuo e ininterrupto, para que desenvolvam atividades pedagógicas na escola. Silvestre (2016, p. 155) caracteriza a imersão como “[ [...] um lugar não mais de observador externo, como é peculiar nos modelos de estágios curriculares mais tradicionais, mas de agente participativo do cotidiano escolar e protagonista de uma práxis pedagógica", mediatizada nas interações verbais entre os interlocutores que produzem enunciações discursivas (BAKHTIN; VOLOCHÍNOV, 1997) no encontro com o outro nos espaços formativos.

De acordo com Passos (2016, p. 169), "tal aproximação pode permitir que os professores e toda a equipe gestora se mobilizem e se integrem num processo de reflexão que articule uma colaboração com vistas a melhorar tanto a situação de trabalho quanto o conhecimento profissional", em processos colaborativos e de aprendizagem, acompanhados de análise e ponderações sobre sua prática pedagógica.

O compartilhamento de saberes, experiências e aprendizagens entre os bolsistas de ID, os coordenadores de área e os professores supervisores coformadores da educação básica integra os processos formativos, proporcionando o desenvolvimento profissional, "por meio de oportunidades para a reflexão sobre prática, críticas partilhadas e mudanças apoiadas" (MIZUKAMI; REALI; REYES; MARTUCCI; LIMA; TANCREDI; MELLO, 2006, p. 129) na relação dialógico-discursiva estabelecida entre os pares, que buscam refletir sobre as práticas formativas no contexto da formação docente. 
O subprojeto do curso de Pedagogia do Campus XII/Uneb "Laboratório de Práticas Pedagógicas" teve início no $2^{\circ}$ semestre de 2012, com a participação de 30 bolsistas de ID, uma bolsista de coordenação de área e três bolsistas de supervisão (OLIVEIRA; REIS, PRADO; CARVALHO, 2017). Posteriormente, as bolsas foram ampliadas, ao ser o projeto contemplado no Edital n 61/2013, da Capes, com a participação de 45 bolsistas de ID, 3 bolsistas de coordenação de área, 8 bolsistas de supervisão e 4 escolas parceiras da rede municipal de ensino de Guanambi. A ampliação do quantitativo de bolsas foi significativa, pois oportunizou a inserção de outros estudantes e professores nesse programa.

Esse subprojeto destaca, no Edital CAPES 061/2013, a necessidade da "realização de ações que propiciem a criação de um vínculo estreito entre o pedagogo, ainda na sua formação e o ambiente escolar, para que os estudantes de Pedagogia possam experimentar o cotidiano escolar, com todas as suas vivências e especificidades”. Buscamos nesse subprojeto: “Oportunizar aos graduandos o contato com a dinâmica da sala de aula da educação infantil e dos anos iniciais do ensino fundamental. Incentivar a prática da investigação em educação, favorecendo a produção científica e divulgação das experiências dos bolsistas" (CAPES, 2013, p. 4).

Buscamos alcançar esses objetivos nas ações desenvolvidas nos encontros formativos do Grupo de Estudo Laboratório de Práticas Pedagógicas e nas atividades realizadas no âmbito escolar, por meio de um projeto colaborativo "em torno de um trabalho conjunto sobre o conhecimento. Importante é construir um percurso integrado e colaborativo, coerente, de formação" (NÓVOA, 2017, p. 1116), que permita construir uma prática discursiva nas relações estabelecidas entre os participantes.

A atuação dos supervisores nas escolas parceiras do Pibid envolveu a articulação das ações nos encontros formativos na universidade e na escola; no planejamento e na reflexão coletiva sobre as atividades de intervenção realizadas nas escolas parceiras, de acordo com a proposta curricular e pedagógica da instituição; no acompanhamento das atividades dos bolsistas de ID no âmbito escolar; na orientação, em parceria com as coordenadoras do subprojeto, de relatórios, relatos de experiências e artigos científicos produzidos.

\section{Metodologia de investigação}

A abordagem de investigação seguida neste trabalho é qualitativa e interpretativa (BOGDAN; BIKLEN, 1994), tendo por base um estudo analítico-descritivo dos relatórios produzidos pelos professores supervisores de atividades do Laprape, no Pibid do curso de 
Pedagogia do Campus XII/Uneb, enviados à Capes nos anos de 2015 a 2017, por meio do Sistema de Relatórios do Pibid.

Segundo Freitas (2007, p. 27), numa pesquisa, "procura-se, portanto, compreender os sujeitos envolvidos na investigação para, através deles, compreender também o seu contexto". Neste estudo, busca-se, pela leitura e a análise dos relatórios, compreender os sentidos atribuídos pelos professores supervisores do Pibid às atividades experienciadas na universidade e nas escolas parceiras do subprojeto Laprape. Do material aqui exposto e relatado constam dados significativos para os processos formativos de professores supervisores que participaram do Pibid e atuam na educação básica.

O procedimento de coleta de dados, conforme Freitas (2007, p. 27-28), “caracteriza-se pela ênfase na compreensão, valendo-se da descrição que deve ser complementada, porém, pela explicação dos fenômenos em estudo, procurando as possíveis relações dos eventos investigados numa integração do individual com o social". Para tanto, os dados colhidos, neste estudo, foram analisados nos relatórios produzidos pelos supervisores do Pibid.

Os oito professores supervisores participantes desta pesquisa foram: Andreia, Ana, Beatriz, Cármen, Joana, Marta, Mateus e Rita, nomes fictícios, para preservar sua identidade. Os espaços formativos em que esses bolsistas atuaram, numa perspectiva de trabalho colaborativo, com a participação da coordenação de área e dos bolsistas de ID, foram quatro escolas parceiras do Pibid/UNEB/Campus XII.

Por meio da estrutura apresentada pelo Sistema do Pibid para elaboração do relatório das atividades desenvolvidas nesse programa, analisamos 24 relatórios produzidos pelos supervisores. Este relato apresenta as descrições das atividades experienciadas na universidade e na escola e as reflexões sobre elas.

Considerando as orientações de Zabalza (2007, p. 58-59), utilizamos, na análise dos diários, as seguintes fases, ao analisar os relatórios do Pibid: uma primeira "leitura exploratória" de todos os relatórios produzidos pelos professores supervisores; uma "segunda leitura, com anotações à margem e seleção de afirmações e dados relevantes", por meio dos registros de tópicos, com destaque no documento em vermelho e azul, referentes às "descrições" e às "reflexões"; leitura seletiva dos dados coletados que demarcaram três categorias apresentadas a seguir, que refletem os sentidos atribuídos pelos professores supervisores do Pibid às atividades experienciadas na universidade e nas escolas parceiras do subprojeto Laprape. 


\section{O que dizem professores supervisores sobre as atividades experienciadas no Pibid?}

Para melhor compreender os sentidos atribuídos pelos professores supervisores do Pibid, selecionamos nos relatórios alguns aspectos para serem compartilhados e discutidos neste texto, nas três categorias apontadas: contribuições da parceria universidade e escola nos processos formativos de professores; grupos colaborativos de estudo no contexto da formação e da prática docente; saberes, experiências e aprendizagens no âmbito do Pibid.

As relações estabelecidas no decorrer das atividades experienciadas pelos supervisores no Pibid perpassaram o "diálogo compreendido não apenas como uma relação face a face, mas de forma mais ampla implicando também uma relação do texto com o contexto" (FREITAS, 2007, p. 30), numa perspectiva dialógica, no encontro com os interlocutores. Nos excertos dos relatórios de Joana e Cármen, percebemos que essas relações no contexto da formação possibilitaram reflexões sobre a prática pedagógica.

Muitas foram as ações do Pibid das quais participei durante o semestre e dentre elas destaco as reuniões semanais com as bolsistas de ID e os momentos de planejamento e elaboração dos projetos e atividades desenvolvidos pelas bolsistas em sala de aula na docência compartilhada. A primeira pela oportunidade de ouvir de cada uma suas impressões e experiências em sala. A segunda, por ter a oportunidade de contribuir com sugestões, ideias para a elaboração de propostas significativas de intervenção para suas atividades docentes [...]. (Supervisora Cármen)

No desenvolvimento de todas as atividades os Bolsistas de Iniciação à Docência procuraram estabelecer um ambiente de responsabilidade, respeito mútuo e entreajuda de modo a favorecer a implementação de estratégias e soluções para os problemas, procurando respeitar as necessidades e ritmos de aprendizagens dos alunos, além de auxiliá-los na superação de eventuais dificuldades. (Supervisora Joana)

Os supervisores apontam como aspectos importantes, nas atividades experienciadas no âmbito do Pibid, a participação nos encontros formativos na universidade e na escola; os momentos de planejamento coletivo e elaboração de projetos e atividades desenvolvidas pelos bolsistas de ID na sala de aula, com a implementação de estratégias e soluções para alguns problemas no processo de ensino e aprendizagem. "E é nessa articulação do problema a ser enfrentado, no estudar, trocar ideias, propor projetos, elaborar materiais, [...] refletir sobre o que fizeram, registrar o que fizeram e o que refletiram sobre o que fizeram que os participantes poderão construir a singularidade [...]" (GARCEZ; SCHLATTER, 2017, p. 25).

As atividades vividas no âmbito do Pibid foram propostas e criadas pelos coordenadores de área, pelos supervisores e pelos bolsistas de ID, numa construção colaborativa de saberes, experiências e aprendizagens do percurso formativo e da prática 
docente, o que possibilita "ao professor avançar em seu desenvolvimento profissional e em sua prática pedagógica" (PASSOS, 2016, p. 178), enriquecido pelas vivências nos encontros formativos na universidade e na escola.

\section{Contribuições da parceria universidade-escola nos processos formativos de professores}

O Pibid proporciona a parceria entre a universidade e a escola, podendo ser considerado como o "terceiro lugar" mencionado por Nóvoa (2017). Para os professores supervisores, esse espaço é propício para a troca de experiências e saberes. Essa parceria é fundamental no contexto da formação e da prática docente, como expressa o relatório de Marta:

Para o bom desenvolvimento de uma prática educativa, deve-se levar em consideração a indissociabilidade de teoria e prática. Nessa perspectiva, realizamos a parceria da Escola com a Universidade, uma vez que o conhecimento é construído a partir de trocas de experiências e de saberes. (Supervisora Marta)

Segundo Nóvoa (2017, p. 1116, grifo do autor), “o segredo deste 'terceiro lugar' está numa fertilização mútua entre a universidade e as escolas, na construção de um lugar de diálogo que reforce a presença da universidade no espaço da profisssão e a presença da profissão no espaço da formação". Também a supervisora Andreia destaca no seu relatório a importância do Pibid nessa parceria universidade-escola: “Com certeza o Pibid é um projeto que veio para enriquecimento e experiência [...], pois acontece uma troca recíproca de experiências vivenciadas. É um avanço na educação, pois a escola precisa desta parceria no processo de ensino e aprendizagem".

Nóvoa (2017, p. 1115) afirma que "é neste lugar que se produz a profissão de professor, não só no plano da formação, mas também no plano da sua afirmação e reconhecimento público". Com efeito, a participação nas ações propostas pelo subprojeto no Campus XII/UNEB foi fundamental para os supervisores na sua formação, afirmação e no reconhecimento público, conforme ilustram os relatórios:

Participei ativamente de todas as ações propostas pelo subprojeto no Campus. Lá nos reunimos com todo o grupo quinzenalmente para orientação, estudos, oficinas, troca de experiências entre escolas e demais demandas que vão surgindo no processo. Participei também de reuniões específicas entre coordenação e supervisão para receber orientações específicas sobre minha atuação e também para troca de experiências e até mesmo dividir as preocupações e desafios do professor supervisor. (Supervisora Cármen) 
Nos grupos de estudos do Laprape, momentos como trocas de experiencias entre as escolas parceiras têm sido fundamentais para o bom desempenho do programa. (Supervisor Mateus)

Como podemos observar, o espaço de formação proporcionado pelo Pibid é um "lugar de ligação entre a universidade, as escolas e as políticas públicas” (NÓVOA, 2017, p. 1116). O trabalho desenvolvido no Laprape possibilitou o encontro de estudantes da graduação, professores da educação básica e professores da universidade, tornando-se um lugar de troca de saberes e experiências nos processos formativos, assumindo "o espaço de atuação como um lugar em que é possível construir e defender novos olhares sobre o fazer ensinar e o fazer aprender" (GARCEZ; SCHLATTER, 2017, p. 26) nas práticas formativas no contexto dos grupos colaborativos.

\section{Grupos colaborativos de estudo no contexto da formação e da prática docente}

Nos grupos colaborativos de estudo "os professores podem potencializar sua capacidade reflexiva sobre aquilo que fazem na sala de aula. A possibilidade de professores universitários participarem com os professores da escola básica nos grupos pode contribuir para um processo de reflexão [...]" (PASSOS, 2016, p. 170).

O Pibid constitui um espaço colaborativo e de estudos, que possibilita a formação dos envolvidos, colocando-os em constante aprendizagem, a partir da reflexão e da crítica sobre a prática pedagógica dos professores. Esse espaço recebeu lugar de destaque nos relatórios dos professores supervisores.

A cada encontro de formação, realizados quinzenalmente, aconteciam grupos de estudo, discussões, relatos de experiências, reflexões sobre a prática de cada um, onde decidiamos coletivamente estratégias para as próximas atividades. [...] Os encontros contribuem para o desenvolvimento pessoal e para o aprimoramento contínuo do trabalho em sala de aula. (Supervisora Joana)

Todas essas vivências trazem reflexos positivos sobre a minha identidade docente. A todo tempo tenho a oportunidade de pensar sobre minha prática e também de crescer com os estudos e as formações. (Supervisora Cármen)

A importância para a formação continuada dos grupos de estudos e da reflexão sobre a própria prática foi destacada pelos professores supervisores nos relatórios aqui parcialmente transcritos. Segundo Passos (2016, p. 171), “o vínculo entre os participantes é essencial e só ocorre quando todos estão envolvidos em objetivos comuns, como, por exemplo, a busca em 
dar significado à visão profissional, que gera reciprocidade e proximidade, como forte sentimento de pertença ao grupo".

É fato que o grupo colaborativo de estudo formado no âmbito do subprojeto Laprape possibilitou o vínculo entre os participantes e a capacidade reflexiva da prática pedagógica utilizada na sala de aula. Também favoreceu a aproximação entre a teoria e a prática, o pensar e o fazer pedagógico, tornando a sala de aula em um local de aprendizagem contínua, conforme expressam os relatórios seguintes:

Os bolsistas apresentam interesse e comprometimento com o subprojeto, dedicam-se semanalmente ao Pibid, participam das reuniões com a supervisão, são assíduos, pontuais e criativos. [...] Os bolsistas têm ainda se empenhado na implementação de novas metodologias de ensino, como elaboração e desenvolvimento de projetos, jogos e atividades diversificadas. (Supervisora Rita)

Por fim, não poderia deixar de relatar o último encontro coletivo ocorrido na escola. Um momento enriquecedor, no qual os professores falaram o quanto consideram importante a presença dos bolsistas, pois ao mesmo tempo que contribuem para a formação dos acadêmicos, também aprendem e que essa troca de conhecimento contribui para a aprendizagem dos alunos. [...] Fica evidente, portanto, a relevância do Pibid na construção da identidade profissional dos futuros professores. (Supervisora Joana)

Os encontros coletivos na escola propiciaram um momento de aprendizagem mútua, em que todos aprendiam. Essa colaboração entre os envolvidos foi primordial para o sucesso do programa e das atividades do Laprape. Pelo que pode ser percebido nos relatórios dos supervisores, não existia o que ensinava e o que aprendia. Os grupos colaborativos de estudo podiam ser considerados um ciclo de aprendizagem, pois todos aprendiam e ensinavam ao mesmo tempo, em um espaço colaborativo. Isso contribuiu para o aprendizado dos estudantes. Segundo Passos (2016, p. 165), “[...] a dimensão formativa de grupos que assim se constituem é potencializada quando seus participantes revelam a superação da forma individualizada com que as decisões sobre o ensinar e sobre o aprender são tomadas no cotidiano escolar".

Os professores supervisores do Pibid, em seus relatos, deixam clara a importância desse espaço de colaboração proporcionado pelo programa. Destacam, ainda, que os participantes com diferentes níveis de experiência ajudaram no desenvolvimento profissional de todos os integrantes do programa e na aprendizagem dos estudantes. Para Passos (2016, p. 168), "esse espaço é atravessado pela dimensão humana e seus ocupantes vão nele e por ele se constituindo como pessoas e como profissionais", como expressa o relatório da supervisora Andreia: "O Pibid foi um dos melhores programas do governo que veio para auxiliar o professor, e ajudá-lo com educação de qualidade, todos saem ganhando, professor com a

RIAEE - Revista Ibero-Americana de Estudos em Educação, Araraquara, v. 16, n. esp. 1, p. 982-998, mar. 2021. e-ISSN: 1982-5587 
ajuda do bolsista e eles aprendendo a exercer a função de professor/educador. Volto a enfocar novamente".

O programa possibilitou a constituição dos envolvidos como pessoas e como profissionais, o que pode ser percebido no trecho do relatório da supervisora. A aproximação da universidade com as escolas, por meio do Pibid, permitiu ultrapassar os limites de uma formação inicial limitada apenas à universidade e desvinculada das práticas pedagógicas. $\mathrm{O}$ Pibid promoveu um espaço de reflexão colaborativa, no qual todos podem crescer no âmbito profissional e no pessoal (PASSOS, 2016). Isso é essencial para a formação inicial e continuada dos professores, pois constitui um processo de valorização e fortalecimento da identidade docente.

Nóvoa (2017, p. 1121) destaca a necessidade "de espaços e de tempos que permitam um trabalho de autoconhecimento, de autoconstrução", isto é, um espaço reflexivo e colaborativo, no qual existam ações para o desenvolvimento profissional e pessoal dos envolvidos.

A realização dos encontros formativos na universidade e nas escolas parceiras do Pibid possibilitou a troca de conhecimentos e de vivências entre os bolsistas do subprojeto, oportunizando o aprendizado sobre a alfabetização e o letramento, a compreensão dos níveis da apropriação da leitura e da escrita, por meio do desenvolvimento de oficinas, dentre outras práticas formativas.

\title{
Saberes, experiências e aprendizagens no âmbito do Pibid
}

Os professores supervisores do programa Pibid destacaram a importância da troca de experiências proporcionada por ele, tornando a sala de aula num espaço de aprendizagem da prática docente, o que pode ser notado no trecho do relatório a seguir:

\begin{abstract}
A sala de aula deve ser um espaço de comunicação sobre a realidade, um espaço de construção e reconstrução de conhecimentos. [...] Nessa direção o subprojeto Laprape em comunhão com a escola, objetivou-se desenvolver uma proposta com um trabalho mais dinâmico e próximo do aluno, possibilitando práticas de leitura e escrita com sentido e significado para proporcionar a leitura como prática social no cotidiano da sala de aula. (Supervisora Ana)
\end{abstract}

Os relatórios dos professores supervisores ressaltam a importância das ações do subprojeto Laprape. Essas ações permitiram a troca de experiências, saberes e aprendizagem da prática docente e, assim, ressaltaram a possibilidade de práticas de leitura e escrita com 
sentido. Garcia-Reis (2016, p. 40) destacam que "as experiências de escrita na universidade podem trazer repercussões essenciais para a escola básica, considerando que os gêneros, como forma de agir socialmente, apresentam-se, tanto na escola como na universidade, como princípio que deve reger essa aprendizagem”.

As experiências de escrita foram apontadas no relatório da supervisora Ana:

Formar leitores é uma tarefa essencial dentro da escola pública. Sendo assim, elaboramos um projeto de leitura para atender as reais necessidades dos educandos. Uma das atividades realizadas foi a contação de histórias, que contribuiu para resgatar em nossos alunos, a ternura, a amorosidade e pureza predominantes na criação existente em cada um de nós.

A escolha do livro: Dona Baratinha, de Ana Maria Machado, proporcionou aos educandos mergulhar no universo da leitura, compreensão $e$ apropriação do sistema alfabético, oralidade e interpretação. Os conhecimentos produzidos pelos alunos resultaram em um dos primeiros passos para o desenvolvimento das habilidades e competências acerca da leitura e da escrita convencional, principalmente.

[...] Compreende-se, portanto, que essa iniciativa é de grande relevância tanto para a formação de novos leitores críticos e reflexivos, quanto para os processos formativos dos licenciandos de Pedagogia bem como dos professores regentes.

De acordo com Silva (2016, p. 11), “as práticas de escrita e de reflexão do professor são necessárias para efetivação da articulação entre saberes teóricos e práticos, podendo resultar ainda na construção de outros saberes em resposta às demandas específicas dos locais de trabalho pedagógico". Nesse sentido, o Pibid tornou-se um espaço de saberes diversos e troca de experiências, proporcionando o avanço na aprendizagem dos estudantes, na formação inicial e continuada dos professores. Os relatos dos supervisores demonstram a importância dessa troca construtiva que ocorreu em todo o tempo do programa e possibilitou o seu desenvolvimento profissional.

O Pibid permitiu, de certa maneira, romper com a ideia de que a formação do professor só acontece nas universidades e que a escola é apenas um espaço para a utilização do que se aprende nos cursos de licenciatura.

Analisando os relatos dos professores supervisores, fica evidente que a escola se tornou um espaço formativo tão importante quanto a universidade. E é nesse espaço que os saberes e as experiências são compartilhados e favorecem a reflexão de todo o processo de aprendizagem. É um espaço de trocas constantes, no qual todos têm algo para ensinar e todos aprendem.

Os seguintes fragmentos dos relatórios produzidos pelas supervisoras destacam a importância do Pibid para a troca de experiências e saberes de todos os participantes:

RIAEE - Revista Ibero-Americana de Estudos em Educação, Araraquara, v. 16, n. esp. 1, p. 982-998, mar. 2021. e-ISSN: 1982-5587 
Segundo semestre de 2017 foi um periodo de experiências significativas e muito aprendizado para nós, bolsistas, onde tive a oportunidade de realizar atividades práticas da vivência docente e também estudar e refletir sobre diversos temas. Participamos da elaboração, planejamento $e$ desenvolvimento de atividades com base no projeto "Brincando também se aprende", desenvolvido pela escola e que contou com a participação dos bolsistas através de propostas de intervenção. Contamos também com a contribuição da coordenadora de área Sandra Oliveira, que realizou na escola uma oficina que teve como tema "A matemática numa perspectiva lúdica" que culminou com a organização e realização da "Gincana matemática lúdica: vamos brincar, jogar e criar com prazer!", no dia 11 de outubro de 2017, que envolveu toda a escola juntamente com os bolsistas de $I D$, supervisão e coordenadora, oportunizando a toda comunidade escolar a possibilidade de vivenciar a matemática dentro de uma proposta lúdica e prazerosa. (Supervisora Cármen)

Tivemos também ricos momentos de aprendizagem e troca de experiências nos encontros de formação do Laprape que nos leva a refletir profundamente sobre a docência através da construção e desconstrução de conceitos. (Supervisora Cármen)

[...] Todas as atividades desenvolvidas pelos pibidianos foram de grande importância para o aprendizado dos alunos, pois durante as mesmas era bastante visivel a atenção dos alunos.

Pude constatar o empenho, a dedicação e o compromisso dos bolsistas, no sentido de planejar e desenvolver as atividades em parceria com o professor da turma. Dessa forma, ampliou-se o seu conhecimento e a sua aprendizagem, e também dos alunos da turma que atuavam como bolsista. (Supervisora Beatriz)

Os momentos de aprendizagem proporcionados pelo Pibid possibilitaram a troca de experiências significativas, ou seja, permitiram "a cada um construir sua posição como profissional, aprender a sentir como professor" (NÓVOA, 2017, p. 1123, grifo do autor). Nesse sentido, a aproximação entre escola e universidade propicia a constituição de espaços formativos, "criando vínculos e cruzamentos sem os quais ninguém se tornará professor" (NÓVOA, 2017, p. 1123). Com efeito, torna-se importante no contexto da formação a valorização dos saberes, de aprendizagens e de experiências das práticas formativas dos professores da educação básica.

\section{Considerações finais}

Pelos dados obtidos nos relatórios produzidos pelos supervisores durante a atuação no Pibid, no período de 2014 a 2017, percebemos que atribuem sentidos às atividades experienciadas na universidade e nas escolas parceiras do subprojeto Laprape, pela participação nos grupos colaborativos de estudo no contexto da formação e da prática 
docente, pelo compartilhamento de saberes, experiências e aprendizagens no âmbito do Pibid, nos encontros formativos na universidade e nas escolas parceiras desse programa.

O Pibid constitui-se como uma alternativa de estabelecimento dessa parceria, aproximando a universidade da educação básica, por meio de um trabalho colaborativo entre estudantes e professores da universidade e professores coformadores da escola, que buscam desenvolver ações coletivas nos espaços formativos.

A participação no subprojeto proporcionou aos professores supervisores um olhar reflexivo sobre a formação e a prática docente, articulando a teoria e a prática nas atividades desenvolvidas no âmbito escolar e nos encontros formativos. Tais eventos possibilitaram o compartilhamento de saberes, experiências e aprendizagens das práticas formativas no contexto dos grupos colaborativos de estudo no âmbito do subprojeto Laprape.

AGRADECIMENTOS: Às professoras da disciplina "Culturas, Linguagens e Formação de Professores", Profa. Dra. Hilda Micarello e Dra. Tânia Guedes Magalhães, do Programa de Pós-Graduação em Educação (PPGE) da Universidade Federal de Juiz de Fora (UFJF), estado de Minas Gerais. Aos professores supervisores participantes do subprojeto do Pibid, no período de 2014 a 2017, em parceria com estudantes/bolsistas de Iniciação à Docência (ID); às professoras formadoras/coordenadoras de área do DEDC XII/UNEB; e aos professores coformadores das quatro escolas da educação básica da rede municipal de ensino de Guanambi, estado da Bahia.

\section{REFERÊNCIAS}

ANDRÉ, M. Políticas de iniciação à docência para uma formação profissional qualificada. In: ANDRÉ, M. (Org.). Práticas inovadoras na formação de professores. Campinas, SP: Papirus, 2016. p. 49-70.

BAKHTIN, M. Estética da criação verbal. Trad. Paulo Bezerra. São Paulo: Martins Fontes, 2011.

BAKHTIN, M.; VOLOCHINOV, V. N. Marxismo e filosofia da Linguagem: problemas fundamentais do método sociológico na ciência da linguagem. Trad. Michel Lahud e Yara Frateschi Vieira. 8. ed. São Paulo: Hucitec, 1997.

BOGDAN, R. C.; BIKLEN, S. K. Investigação qualitativa em educação: uma introdução à teoria e aos métodos. Trad. Maria João Alvarez, Sara Bahia dos Santos e Telmo Mourinho Baptista. Portugal: Porto Editora, 1994. 
BRASIL. Programa Institucional de Bolsa de Iniciação à Docência. Portaria n. 096, de 18 de julho de 2013. Regulamento do Programa Institucional de Bolsa de Iniciação à Docência. Brasília, DF: CAPES/PIBID, 2013. Disponível em:

http://www.capes.gov.br/images/stories/download/legislacao/Portaria_096_18jul13_AprovaR egulamento PIBID.pdf. Acesso em: 10 set. 2019.

CAPES. Programa Institucional de Bolsa de Iniciação à Docência. Detalhamento do subprojeto Laboratório de Práticas Pedagógicas. Edital CAPES 061/2013. Brasília, DF: CAPES, 2013.

FREITAS, M. T. A. A perspectiva sócio-histórica: uma visão humana da construção do conhecimento. In: FREITAS, M. T. A.; SOUZA, S. J.; KRAMER, S. (Org.). Ciências humanas e pesquisa: leituras de Mikhail Bakhtin. 2. ed. São Paulo: Cortez, 2007. p. 26-38. GARCEZ, P. M.; SCHLATTER, M. Professores-autores-formadores: princípios e experiências para a formação de profissionais de educação linguística. In: MATEUS, E.; TONELLI, J. R. A. (Org.). Diálogos (im)pertinentes entre formação de professores e aprendizagem de línguas. São Paulo: Blucher, 2017. p. 13-36.

GARCIA-REIS, A. R.; MAGALHÃES, T. G. As experiências de escrita na formação de professores de Língua Portuguesa: uma prática no curso de Letras da UFJF. In: GARCIAREIS, A. R.; MAGALHÃES, T. G. (Org.). Letramentos e práticas de ensino. Campinas, SP: Pontes Editores, 2016. p. 35-52.

MICARELLO, H. A. L. S.; MAGALHÃES, T. G. Letramento, linguagem e escola. Revista Bakhtiniana, São Paulo, v. 9, n. 2, p. 150-163, ago./dez. 2014.

MIZUKAMI, M. G. N.; REALI, A. M. M. R.; REYES, C. R.; MARTUCCI, E. M.; LIMA, E. F.; TANCREDI, R. M. S. P.; MELLO, R. R. Escola e aprendizagem da docência: processos de investigação e formação. 2. reimpr. São Carlos: EdUFSCar, 2006.

NÓVOA, A. Firmar a posição como professor, afirmar a profissão docente. Cadernos de Pesquisa, São Paulo, v. 47, n. 166, p.1106-1133, out./dez. 2017.

OLIVEIRA, S. A. O.; REIS, S. M. A. O.; PRADO, J. R.; CARVALHO, M. F. P. Subprojeto Laboratório de Práticas Pedagógicas do Pibid/Uneb Campus XII no contexto da formação de estudantes do curso de Pedagogia. In: SEMINÁRIO NACIONAL, 6.; SEMINÁRIO INTERNACIONAL, 2017, Vitória da Conquista. Anais [...]. Vitória da Conquista: PPGED/UESB, 2017. Disponível em:

http://anais.uesb.br/index.php/semgepraxis/article/view/7453. Acesso em: 28 nov. 2019.

PASSOS, L. F. Práticas formativas em grupos colaborativos: das ações compartilhadas à construção de novas profissionalidades. In: ANDRÉ, M. (org.). Práticas inovadoras na formação de professores. Campinas, SP: Papirus, 2016. p. 165-188.

SILVA, W. R. Letramento científico na formação inicial do professor. Revista Práticas de Linguagem, v. 6, escrita discente, 2016.

SILVESTRE, M. Aparecida. Práticas de estágios no Programa de Residência Pedagógica da UNIFESP/Guarulhos. In: ANDRÉ, M. (org.). Práticas inovadoras na formação de professores. Campinas, SP: Papirus, 2016. p. 147-164. 
ZABALZA, M. A. Diários de aula: um instrumento de pesquisa e desenvolvimento pessoal. Porto Alegre: Artmed, 2007.

\section{Como referenciar este artigo}

OLIVEIRA, S. A.; REZENDE, D. P. L.; CARNEIRO, R. F. Processos formativos de professores supervisores no âmbito do PIBID: sentidos atribuídos às atividades experienciadas na universidade e na escola. Revista Ibero-Americana de Estudos em Educação, Araraquara, v. 16, n. esp. 1, p. 982-998, mar. 2021. e-ISSN: 1982-5587. DOI: https://doi.org/10.21723/riaee.v16iEsp.1.14932

Submissão em: 20/06/2020

Revisões requeridas em: 16/09/2020

Aceito em: 03/11/2020

Publicado em: 01/03/2021 